\title{
Impacts of Wind Power Variations on Frequency Related Power System Operations
}

\author{
Shahida Khatoon \\ Department of Electrical Engineering \\ Faculty of Engineering and Technology \\ Jamia Millia Islamia \\ Jamia Nagar, New Delhi-110025, India
}

\begin{abstract}
Wind power is seen as the most cost effective way to generate electricity from renewable sources. The wind turbine prime mover, wind, is uncontrollable as compared to the conventional power plant prime mover. Therefore, it becomes very important to carry out investigations on the dynamic behavior of wind power generating systems. In this paper, the dynamic model of 1 MVA unit is extrapolated from $100 \mathrm{~kW}$ unit existing in NASA -Lewis Research Centre. The various types of investigations are carried out to study the dynamic performance of various states of the model considering variations in the wind speed. At the outset of the work, state space model of the system is developed. To study the dynamic behavior of the system, optimal controllers are designed using full state feedback control strategy. Following the controller designs, the closed loop system eigenvalues and dynamic response plots are obtained.
\end{abstract}

The Strip Eigenvalue Assignment method is applied to design sub-optimal controllers using feedback of few states which are accessible for their observation and measurement. The comparative study of closed loop eigenvalues and dynamic response plots obtained for various operating conditions shows a comparable system dynamic performance.

The optimal controllers are designed for various operating conditions using pole placement technique. The dynamic response plots and closed loop eigenvalues are obtained for various system states considering various operating conditions. The investigations of these reveal that the implementation of optimal controllers offer not only good dynamic performance, also ensure system dynamic stability.

Keywords- The Strip Eigenvalue Assignment method; dynamic response plots; optimal controllers; eigenvalue

\section{INTRODUCTION}

Electric power systems, consists of components that transform other types of energy into electrical energy and transmit this energy to consumers. The production and transmission of electricity is relatively efficient and inexpensive, although unlike other forms of energy, electricity is not easily stored and thus must generally be used as it is being produced.

The system frequency is common throughout the interconnected power system with normally scheduled tie- line loadings. When both frequency and tie- line loadings are maintained on schedule then only the control system functions properly.
As almost all the power systems operate at alternating current, the frequency changes momentorarily only when the generator increases or decrease load, which is also in minor, otherwise frequency is same throughout the system. When system frequency increases or decreases, the speed of the connected units changes by the same amount electrically.

\section{LITERATURE REVIEW}

The use of non renewable energy resources is resulting in harmful emissions and producing harmful side effects. Due to increasing environmental concern and also due to limited availability of conventional resources for fuel, more and more attention now a days is paid to renewable resources of energy like solar, wind, ocean, geothermal etc. [4-7]. These sources are available in abundance as well as they are non- polluting.

The integration of wind power into utility is increased with large number of new installations of wind turbines. The special characteristic of wind, differentiating it from others is the variability of wind speed, the source of energy. The dynamic stability of the wind turbine generator thus become very important [8], as the dynamic stability affects the synchronization of different units in the system. Most important it affects the dynamic stability of the system to which it is connected. It is seen that there are modal frequencies lying in the range of concern for large interconnected power system [23]. Power system stabilizers (PSS) can be used for increasing the damping torque of wind turbine generator and the PSS design is based on one operating point, and away from this is a compromise [1].there are two main categories adopted in power system control, centralized and decentralized. A centralized control is slow and involves long distance transmission., hence difficult to apply to fast on- line power system control Decentralized control is more efficient, it takes directly locally available signals from local devices. Hence a coordination among local controllers is necessary, with the fast growing embedded and interconnected generation [2,3,12].a controlled system means the generation is meeting the load demand, that there exists a steady state frequency system [13].the weighing factors have a powerful impact on the system response. These factors can be obtained by classical techniques such as step response [18]. The power system dynamics is essential to be understood for stable system operation. The optimization of the existing resources is necessary for the long term stable operation of the power system. To avoid unnecessary mechanical stresses and to operate within stability limits different units in the system should run in synchronism. Therefore the dynamic performance of the wind turbine generator is of concern as it affects the dynamic stability of the system to which it is connected [1]. 
The wind turbine generator used is a synchronous generator [30] with a static excitations system. The transient stability signals derived from speed, terminal frequency, or power are superposed on the normal voltage signal of voltage regulator, which provides additional damping to the oscillations [29, 31] The wind generator operates in parallel with the utility grids. Thus, the synchronization of the wind turbine generator with power system under variable conditions, ie; variable frequency and variable wind speeds, are important for system stability.

A wind turbine generator exhibits an unsteady input behavior mainly because of unsteady wind speeds. This unsteady behavior causes severe oscillations. The transient stability signals derived from speed and terminal frequency are superposed on the normal voltage error signal of automatic voltage regulator (AVR), thus providing damping to these oscillations. Thus the terminal voltage of both the conventional and wind turbine generator can be kept within satisfactory limits by AVR [32].

Also the damping can be provided by using an output feedback and strip eigen value assignment technique. The eigenvalues location affects the dynamics of the system. Therefore it is necessary to locate the eigenvalues at some desired positions. The exact location of all eigenvalues at each operating point is difficult to attain. But a satisfactory response for both transient and steady state can be obtained by placing all eigen values within a suitable region in complex s - plane [20 - 22].

\section{POWER SYSTEM CONTROL}

Extensive system interconnection characterizes the today's modern power system. It is necessary to optimally utilize the existing resources, for which it's extensive control is required. Power system dynamics has an important bearing on the satisfactory system operation. The dynamic behavior of the system is quite complex and a good understanding is essential for proper system planning and system security. The present day power system is an interconnected power system, and has several advantages. Power system control is very much required to maintain demand, while the system frequency, voltage level and security are maintained. The overall system control is based on a combination of manual intervention, feedback loops, optimization techniques and load demand. The control of frequency and power exchange can be done by load frequency control. The need for direct control of network voltage is usually done by automatic voltage regulating equipments.

The system control is based on the frequency intervention of the physical phenomenon involved. Reactive power distribution generally do not affect the system operating cost significantly, but an optimum allocation may be important for maintaining steady state stability and voltage levels of the system [4]

\subsection{Control Strategies}

A control system must guarantee first the stability of the closedloop system. For linear systems, this can be obtained by pole placement technique. Non-linear control systems use specific theories to ensure. The main control techniques are given below:

1) Adaptive Control:uses on-line identification of the process parameters, or modification of controller gains, thereby obtaining strong robustness properties

2) Hierarchical Control:A Hierarchical control system is a type of control system in which a set of devices and governing software is arranged in a hierarchical tree. When the links in the tree are implemented by a computer network, then that hierarchical control system is also a form of Networked control system.

3) Intelligent Control:Intelligent control use various $\mathrm{AI}$ computing approaches like neural networks, Bayesian probability, fuzzy logic, machine learning, evolutionary computation and genetic algorithms to control a dynamic system.

4) Optimal Control: Optimal control is a particular control technique in which the control signal optimizes a certain "cost index". Two optimal control design methods have been widely used in industrial applications, as it has been shown they can guarantee closed-loop stability. These are Model Predictive Control (MPC) and Linear-Quadratic-Gaussian control (LQG). The first can more explicitly take into account constraints on the signals in the system, which is an important feature in many industrial processes. However, the "optimal control" structure in MPC is only a means to achieve such a result, as it does not optimize a true performance index of the closed-loop control system.

5) Robust Control: Robust control deals explicitly with uncertainty in its approach to controller design. Controllers designed using robust control methods tend to be able to cope with small differences between the true system and the nominal model used for design.

6) Stochastic Control: Stochastic control deals with control design with uncertainty in the model. In typical stochastic control problems, it is assumed that there exist random noise and disturbances in the model and the controller, and the control design must take into account these random deviations [5].

\subsection{Classical Control Strategies}

Control is a general term for the theory and techniques to change the dynamic performance of a system by imposing certain inputs on the system to satisfy certain requirements to their best. To describe a linear control system, the modeling method governs the following properties of classical control theory:

- it transforms high order differential equation of time t into polynomials of complex variable s.

- Since the transfer function is obtained from the Laplace transformation of the linear time invariant ordinary differential equation, they are equivalent to each other. Therefore the system that the transfer function can model, are only linear constant control systems.

- Since the transfer function is the ratio between the Laplace transformation of the output and input, this theory is applicable to only single- input and singleoutput systems.

- $\quad$ The modeling method of the transfer function can only be used to investigate and analyze the relation between input and output, hence it conceals the internal dynamic behavior of the system.

With the increasing complexity and requirement of stringent precision and dynamic performance, more advancement in productivity and technology taking place which could be well applicable to multi- input and multi- output systems. All these facts lead to the development of modern control theory, namely multi variable linear control theory [16]. 
The classical control theory was expressed in the frequency domain and the s-plane using the methods of Nyquist, Bode, Nichols and Evans. All that is needed is the magnitude and phase of the frequency response, or the poles and zeroes of the open loop transfer function. This is very implementable for single-input/single-output systems since all these elements, the frequency response, and poles and zeroes of a transfer function, can accurately be determined. More than this, robust design is implemented using notions of gain and phase margin. To determine the transfer function of complex systems the block diagram algebra is very intensive used. It is not necessary for an internal description of the system dynamics; that is, only the input/output behavior of the system is needed [17].

\subsection{Optimal Control Strategy}

The above mentioned classical techniques, which deals with SISO systems, do not give satisfactory response when deal with MIMO power systems, as they becomes more complex. Optimal control recognizes the random behavior of the system and attempts to optimize response or stability on an average rather than with assured precision. The optimal control theory provides a comprehensive, consistent, and flexible design approach. The classical response criteria such as step response are helpful in determining what values to use in quadratic cost function weighting matrices. These weighting factors have a powerful and direct effect on achieving desired response [18].

\subsection{Optimal Controller Design Using Full State Feedback Control Strategy}

To design an optimal regulator, the modern control theory requires the development of dynamic system model in state variable form. The regulator design of higher order non- linear system model, results in complex computations. Hence the linearization of the system equations about an operating point was proposed, and then the linear state- regulator theory is applied to obtain the desired control law. However this may result in higher cost complexity problems. The regulator designed with reduced number of state variables may not be optimal in realistic situations [19].

A linear time invariant power system in state space is represented by following differential equations;

$$
\begin{gathered}
\dot{X}(t)=A x(t)+B u(t)+T d(t) \\
y(t)=C x(t)
\end{gathered}
$$

the control law is given by

$$
\mathrm{u}=-\mathrm{kx}
$$

for full state vector feedback

$$
\mathrm{u}=-\mathrm{k} \mathrm{y}
$$

for output feedback problem to minimize the performance index

$$
J=\int_{0}^{\infty}(x T Q x+u T R u) d t
$$

Subjected to system dynamic constraints (3.4) and (3.5). the augmented cost function for the performance index $\mathrm{J}$ is given by

$$
J=\int_{0}^{\infty}[(x T Q x+u T R u)+\lambda T(A x+B u-x)] d t
$$

Defining Hamiltonian as

$$
\mathrm{H}=1 / 2(\mathrm{xT} \mathrm{Q} x+\mathrm{uT} \mathrm{Ru})+\lambda \mathrm{T}(\mathrm{A} x+\mathrm{Bu})
$$

Using linear state regulator approach, let $\mathrm{u}^{*}$ be an admissible control that drives the system from an initial point $\mathrm{x} 0$, where * indicates that $\mathrm{u}=\mathrm{u}^{*}$. For $\mathrm{u}^{*}$ to be optimal, the variables must satisfy the following relations;

$$
\begin{aligned}
& \mathrm{x}^{*}=\partial \mathrm{H} / \partial \lambda\left(\mathrm{x}^{*}, \lambda^{*}, \mathrm{u}^{*}\right) \\
& *=-\partial \mathrm{H} / \partial \mathrm{x}\left(\mathrm{x}^{*}, \lambda^{*}, \mathrm{u}^{*}\right)
\end{aligned}
$$

And the function $\mathrm{H}\left(\mathrm{x}^{*}, \lambda^{*}, \mathrm{u}^{*}\right)$ must be minimum. Hence we get

$$
\begin{aligned}
\partial \mathrm{H} / \partial \mathrm{u} & =0=\mathrm{Ru}+\mathrm{BT} \\
\mathrm{U}^{*} & =-\mathrm{R}-1 \mathrm{BT}
\end{aligned}
$$

From (3.9) and (3.10) the differential equation obtained in $\mathrm{x}^{*}$ and * must satisfy

$$
\begin{gathered}
*=-\operatorname{Ar} *-\mathrm{Q} \mathrm{x}^{*} \\
\mathrm{x}^{*}=\mathrm{A} \mathrm{x}{ }^{*}-\mathrm{BR}-1 \mathrm{BT} \lambda^{*} \\
\text { Assuming } \lambda \tilde{=} \mathrm{px}
\end{gathered}
$$

Substituting for the costate in terms of $\mathrm{x}$ in equation 3.15 , we get

$$
\begin{gathered}
\mathrm{Px}^{*}+\mathrm{px}^{*}=\mathrm{AT} \mathrm{px} *-\mathrm{Q} \mathrm{x}^{*} \\
\mathrm{x}^{*}=\mathrm{Ax} *-\mathrm{BR}-1 \mathrm{BT} \mathrm{px}^{*}
\end{gathered}
$$

Substituting $\mathrm{x}^{*}$ in equation 3.16 , the vector $\mathrm{x}$ gives the $\mathrm{n} \mathrm{x} \mathrm{n}$ matrix differential equation as

$$
p+p A-p B R-1 B T p+A T p+Q=0
$$

This differential equation is called the Riccati equation [19].

Thus the closed loop system is defined as

$$
\dot{\mathrm{X}}=\mathrm{Gx}
$$

Where

And

$$
\begin{aligned}
& \mathrm{G}=\mathrm{A}-\mathrm{B} \mathrm{k} \\
& \mathrm{k}=\mathrm{R}-1 \mathrm{BT} \mathrm{p}
\end{aligned}
$$

\subsection{Suboptimal Controller Design Using Output Feedback Control Strategy}

An optimal solution may not be the best solution in all circumstances, if all the states $\mathrm{x}(\mathrm{t})$ are not accessible for feedback, one has to go for a state observer whose complexity is comparable to that of the system itself. Hence a procedure is required that relies on the use of feedback from only the accessible state variables constraining the gain elements of matrix $\mathrm{k}$ corresponding to the inaccessible state variables to have zero value. It is a method of obtaining the solution of a 
control problem when some elements of the feedback gain matrix $\mathrm{k}$ are constrained.

The system considered here may be represented by

$$
\dot{\mathrm{X}}=\mathrm{Ax}+\mathrm{Bu} ; \quad \mathrm{x}(0)=\mathrm{x} 0
$$

The performance index is

$$
J=1 / 20 \int \infty(x T Q x+u T R u) d t
$$

The multiplication by $1 / 2$ does not affect the minimization problem, but helps in mathematical manipulations.

With the linear feedback law or optimal control law for a linear combination of the state variable

$$
\mathrm{u}(\mathrm{t})=\mathrm{kx}(\mathrm{t})
$$

The closed loop system is described by

$$
\dot{\mathrm{X}}(\mathrm{t})=(\mathrm{A}+\mathrm{Bk}) \mathrm{x}(\mathrm{t})
$$

Substituting for control vector $\mathrm{u}$ in performance index $\mathrm{J}$ in equation 3.25 , we have

$$
\begin{gathered}
J=1 / 20 \int \infty(x T Q x+x T k T R k x) d t \\
J=1 / 20 \int \infty(x T(Q+k T R k) x d t
\end{gathered}
$$

Assuming a Lyapunov function

$$
V(x(t))=1 / 20 \int_{\infty} x T(Q+k T R k) x d t
$$

Or

$$
\dot{\mathrm{V}}_{(\mathrm{x}(\mathrm{t}))=-1 / 2 \mathrm{xT}(\mathrm{Q}+\mathrm{kTR} \mathrm{k}) \mathrm{x}}
$$

Since $\dot{\mathrm{V}}(\mathrm{x})$ is a quadratic in $\mathrm{x}$ and the system equation is linear, let us assume that $\mathrm{V}(\mathrm{x})$ is also given by the quadratic form

$$
\mathrm{V}(\mathrm{x})=1 / 2 \mathrm{xT} P \mathrm{x}
$$

Therefore

$$
\dot{\mathrm{V}}_{(\mathrm{x})=-1 / 2\left(\dot{\mathrm{X}}_{\mathrm{T}} \mathrm{P} \mathrm{x}+\mathrm{xT} \mathrm{P} \mathrm{x}\right)}
$$

Substituting for $\mathrm{x}$ from equation 3.26, we have

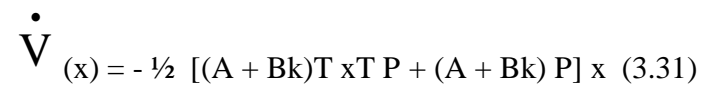

Comparing this result with equation 3.28 , we have

$$
-1 / 2 \times \mathrm{T}(\mathrm{Q}+\mathrm{kT} \mathrm{R} \mathrm{k}) \mathrm{x}=1 / 2 \mathrm{xT}[(\mathrm{A}+\mathrm{Bk}) \mathrm{T} \mathrm{P}+\mathrm{P}(\mathrm{A}+\mathrm{Bk})] \mathrm{x}
$$

Since the above equality holds for arbitrary $\mathrm{x}(\mathrm{t})$, we have

$$
(\mathrm{A}+\mathrm{B} k) \mathrm{T} P+\mathrm{P}(\mathrm{A}+\mathrm{B} \mathrm{k})+\mathrm{kT} \mathrm{R} \mathrm{k}+\mathrm{Q}=0
$$

This equation is of the form of the Liapnov equation. From this equation the elements of $\mathrm{P}$ can be determined as function of the feedback matrix $\mathrm{k}$. the value of the performance index for system trajectory starting at $\mathrm{x}(0)$ is $\mathrm{V}(\mathrm{x}(0))$. Therefore

$$
\mathrm{J}=1 / 2 \times \mathrm{T}(0) \operatorname{Px}(0)
$$

Thus a suboptimal control law may be obtained by minimizing $\mathbf{J}$ with respect to all available elements $\mathrm{k}_{\mathrm{ij}}$ of $\mathrm{k}$, ie; by setting

$$
\partial[\mathrm{xT}(0) \operatorname{Px}(0)] / \partial \mathrm{kij}=0
$$

Hence, when the configuration of the controller is constrained, a solution which is independent of the initial conditions can no longer be obtained [20].

\subsection{Suboptimal Controller Design Using Strip Eigenvalue Assignment Method}

The linear systems are the approximations of the non - linear systems. The linear systems are influenced by the locations of eigenvalues. Therefore, for a system to get good response, both in transient and steady states, it is necessary to locate all eigenvalues in desired positions. Due to approximations, it is difficult to attain the exact locations of all eigenvalues. Hence it is sufficient that all eigenvalues are placed within a suitable region in complex s- plane, using strip eigenvalue assignment method.

The linear quadratic control is used to optimize the closed loop system, such that the eigenvalues lies within a vertical strip in the complex s- plane [21]. The output feedback controller is preferred as compared to the state feedback controller; since it is not possible to measure all the states of the system.

A power system can be described by a completely observable and controllable linear time invariant system, in state space as follows;

$$
\begin{gathered}
\dot{\mathrm{X}}(\mathrm{t})=\mathrm{Ax}(\mathrm{t})+\mathrm{Bu}(\mathrm{t})+\mathrm{Td}(\mathrm{t}) \\
\mathrm{y}(\mathrm{t})=\mathrm{C} \mathrm{x}(\mathrm{t})
\end{gathered}
$$

The quadratic cost function for the system in (3.36) be

$$
J=0 \int \infty(x T Q x+u T R u) d t
$$

where the weighting matrices

$\mathrm{Q}$ - $\mathrm{n} \times \mathrm{n}$ nonnegative definite symmetric matrix

$\mathrm{R}$ - $\mathrm{m}$ x m positive definite symmetric matrix

In optimal control theory application, the term $\operatorname{Td}(\mathrm{t})$ is eliminated by redefining the states and controls in terms of their steady state values occurring after the disturbance is applied [20]. The equation (3.34) can be re written as;

$$
\dot{\mathrm{X}}(\mathrm{t})=\mathrm{Ax}(\mathrm{t})+\mathrm{Bu}(\mathrm{t}), \mathrm{x}(0)=0
$$

and equation 3.35 will remain same. $\mathrm{P}$ is a positive definite symmetric matrix, and solution of the following Riccati equation:

$$
\text { AT P+ P A - P B R-1 BT P + Q = On }
$$


The full state feedback control law which minimizes the performance index in equation 3.38 is stated as

$$
u(t)=-G y(t)=-G C x(t)
$$

In conventional optimal analysis, matrices $\mathrm{Q}$ and $\mathrm{R}$ are commonly chosen as diagonal matrices. The system performance can be improved by shifting the eigenvalues $\Lambda$ (ABG) of the closed loop system to a desired region. From this, the weighting matrix $\mathrm{R}$ is set as an identity matrix with weights states for all inputs, and Q matrix must be given. For the system to be relatively stable, $h \geq 0$. Then the closed loop system matrix

$$
\mathrm{AC}=\mathrm{A}-\mathrm{B} \mathrm{G} \tilde{\mathrm{P}}
$$

has all its eigen values lying on the left side of the $\quad-h$ vertical line as shown in Fig .3.1, where the matrix $\tilde{\mathrm{P}}$ is the solution of the following Riccati equation:

$$
(\mathrm{A}+\mathrm{h} 1 \mathrm{In}) \mathrm{T} \tilde{\mathrm{P}}+\tilde{\mathrm{P}}(\mathrm{A}+\mathrm{h} 1 \mathrm{In})-\tilde{\mathrm{P}} \mathrm{B} \mathrm{R}-1 \mathrm{BT} \tilde{\mathrm{P}}+\mathrm{Q}=\mathrm{On}
$$

The unstable eigenvalues of the closed loop system $(\mathrm{A}+\mathrm{h} 1$ $I_{n}$ ) are shifted to their mirror image position with respect to the $-\mathrm{h}$ vertical line [21-23].

Assume two positive real values $\mathrm{h} 1$ and $\mathrm{h} 2$ to define an open vertical strip of $[-\mathrm{h} 1,-\mathrm{h} 2]$ on the negative real axis as shown in Fig. 3.2, with $\hat{A}=(A+h 1$ I $)$. The control law is changed to be

$$
\begin{gathered}
u(t)=-G y(t)=-G C x(t)=-\mu \tilde{F} x(t) \\
G=\mu \tilde{F} C+
\end{gathered}
$$

Where $\mathrm{C}+$ is the pseudo- inverse of $\mathrm{C}$.

$$
\begin{aligned}
\mu & =1 / 2+(\mathrm{h} 2-\mathrm{h} 1) / 2 \operatorname{tr}(\hat{\mathrm{A}}+) \\
& =1 / 2+(\mathrm{h} 2-\mathrm{h} 1) / \operatorname{tr}(\mathrm{B} \tilde{\mathrm{F}})
\end{aligned}
$$

And,

$$
\tilde{\mathrm{F}}=\mathrm{R}^{-1} \mathrm{BT} \tilde{\mathrm{P}}
$$

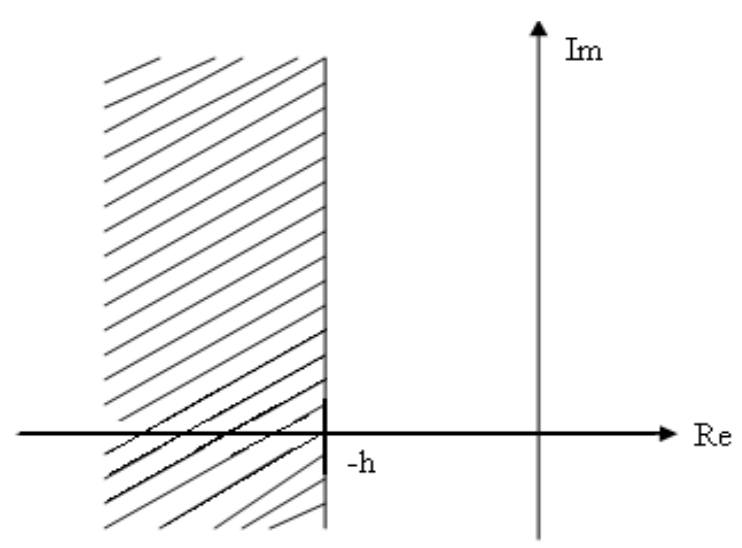

Figure 1. Vertical line in a complex s- plane

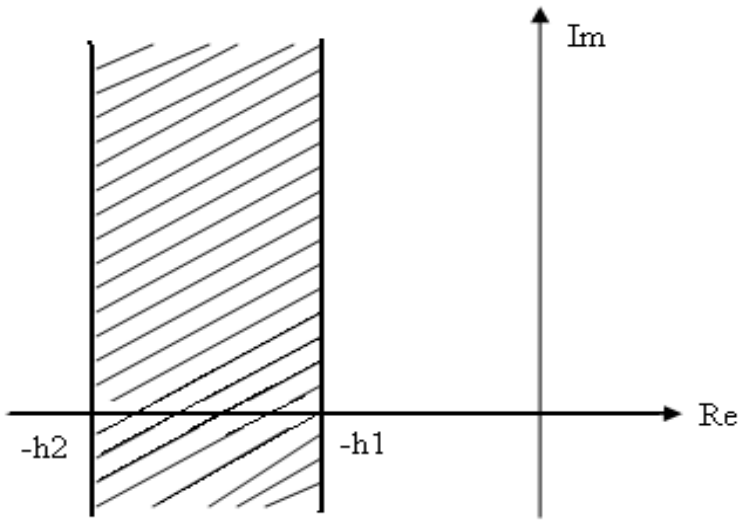

Figure 2.

Complex s- Plane with vertical strip

Thus, the resulting optimal closed-loop system becomes

$$
\dot{X}(t)=(A-B G C) x(t)
$$

The feedback control is used to find out the output feedback gain vector $G$, to place the eigen values of the closed loop system at some desired locations, in the vertical strip between h1 and h2 as shown in Fig. 3.2, to stabilize the system with acceptable transient behavior.

\section{SIMULATION RESULTS}

The state space model of the system under consideration is developed in Chapter- 4. In this chapter, (i) optimal controllers using full state feedback control strategy (ii) sub-optimal controllers using Strip Eigenvalue Assignment method considering output feedback control strategy and (iii) optimal controllers using pole placement technique are designed and implemented in the wake of system perturbation. Various system operating conditions are identified based on the variation in wind power generation. The reactiv( 8 . $45 y$ wer is set to remain constant. The closed loop system eigenvalues and dynamic response plots are obtained for various system states. The investigations of these results have been carried out using different characteristic parameters of the results. The real power variation results in variation in the frequency; the impact of wind power generation on system frequency $(\omega)$ has been investigated.

The simulation results are obtained using MATLAB Control Toolbox. The simulation results obtained are presented as follows :

\section{DISCUSSION OF RESULTS}

The investigations are carried out for $\omega$ considering variation in Po. From the inspection of plots, it is seen as the value of Po is increasing, the settling time is decreasing. The same argument is supported by Table $5.8-5.15$. The inspection of rising time and settling time in these Tables reveals that the optimal and sub optimal controllers offer response plots has comparable rising and settling time, whereas the controllers designed using pole placement technique has resulted in a considerable improvement change, when compared to those obtained with others controllers. The peak amplitude for $\delta$ is considerably large. Incase of $\omega$, the magnitudes of first peak are comparable with all the controllers. 
Although the performance of the output feedback controller is acceptable for different operating points, the performance is considerably improved by introducing pole placement technique, where all the poles are shifted to some desired place to make the system more stable. The trend of the peak shows a considerable improvement, when the dynamic responses obtained using optimal controller and suboptimal controller are compared with pole placement technique.

\section{CONCLUSIONS}

As discussed in detail earlier in the thesis, the wind power has been one of the most important forms of energy due to various environmental, technical and economic reasons. It is envisaged that it will have an impact on energy policy of the country in near future. Therefore, it becomes very important to put more efforts on carrying out studies regarding the generation and control of wind energy system including its dynamic behavior. In the present work, a wind turbine generator model is considered for the investigation. The various types of investigations are carried out to study the dynamic performance of various states of the model considering variations in the wind speed. The variable wind speed results in variable frequency generation. Therefore, main thrust is given to study the frequency related impacts of wind power variations on system dynamics.

At the outset of the work, state space model of the system is developed. To study the dynamic behavior of the system, optimal controllers are designed using full state feedback control strategy. Following the controller designs, the closed loop system eigenvalues and dynamic response plots are obtained. The investigations of these reveal that the implementation of optimal controllers offer not only good dynamic performance, also ensure system dynamic stability.

Practically it is not possible always to measure all the system states, thus the concept of above designed optimal controllers does not seems practical. Therefore, sub-optimal controllers are designed using feedback of those system states which are accessible for their observation and measurement. The Strip Eigenvalue Assignment Method is applied to design suboptimal controllers using feedback of few states which are accessible for their observation and measurement. The comparative study of closed loop eigenvalues and dynamic response plots obtained for various operating conditions shows a comparable system dynamic performance.

As the system dynamic model is not stable, therefore, pole placement technique is applied to place the poles of the system in stable region. The optimal controllers are designed for various operating conditions using pole placement technique. The dynamic response plots and closed loop eigenvalues are obtained for various system states considering various operating conditions. The comparative study of response plots and closed loop eigenvalues is obtained with (i) optimal controllers designed using full state feedback control strategy (ii) suboptimal controllers designed using Strip Eigenvalue Assignment method considering output feedback control strategy and (iii) optimal controllers designed using pole placement technique. The designed controllers ensured the closed loop system stability in the study. Furthermore, the impact of wind power on frequency of the system is seen visible. The various controllers designed in the work are found to exhibit their effect under various operating conditions.

To study the impacts on frequency with the variation in wind speed and hence power, the system is investigated at different operating conditions corresponding to different real power values, keeping the reactive power as constant. The investigations show that with all controllers, the settling time is reduced as the Po is increased. However, it is interesting to note that the settling time has reverse trend at Po $=1$ p.u. The peaks with both optimal and suboptimal controllers are comparable, whereas the optimal controller designed using pole placement technique exhibits a considerable improvement as compared to those obtained with other controllers.

\section{REFERENCES}

[1] H. N. Al- Duwaish, Z. M. Al- Hamouz \& S. M. Badran, "Adaptive Output Feedback Controller For Wind Turbine Generators Using Neural Networks", Electric Machines And Power Systems, Vol. 27, pp. 465- 479, 1999

[2] S. Sivanagaraju, S. Satyanarayana, Electric Power Transmission and Distribution, Pearson, 1st edition, Singapore, 2007.

[3] P. Schavemaker \& L. V. D Sluis, Electrical Power System Essentials, Wiley Eastern Limited, 1st edition, Netherland, June 2008.

[4] A. Chakrabarti \& S. Halder, Power System Analysis : Operation and Control , PHI, 2nd edition, New Delhi, 2007.

[5] M. Gopal, Modern Control System Theory, Wiley Eastern Limited, 1st edition, IIT Delhi, December 1985.

[6] K. Sharma, "Renewable Energy: The Way to Sustainable Development", Electrical India, vol. 42 No. 14, pp.20- 21, July 2002.

[7] G. D. Rai, Non - Conventional Sources of Energy, Khanna Publishers, New Delhi, 4th edition, 2006.

[8] K.S. Sidhu -Director / Research, Non-Conventional Energy Resources, Punjab Electricity Board, PEC Campus, Chandigarh.

[9] J. M. Carrasco, E. Galván, R. Portillo, L.G. Franquelo \& J.T.Bialasiewicz, "Power Electronic Systems for the Grid Integration of Wind Turbines", Proceedings of the 32nd Annual Conference of the IEEE Industrial Electronics Society. IECON'Paris (France), pp. 4182-4188, November, 2006.

[10] R. Zavadil, N. Miller, A. Ellis \& E. Muljadi, "Making Connections with Wind Power", IEEE Power \& Energy Magazine, pp.26-36, 2005.

[11] J. G. Slootweg, "Wind Power Modelling and Impact on Power System Dynamics", Ph. D Thesis, Technical University, Dleft, Netherland, December, 2003.

[12] F. Wang, "The 'Third-Category' Method and Multiagent", System Theory in Power System Applications, (The University of Bath, UK), Power Engineering Society General Meeting, IEEE, pp. 1042-1043 Vol. 2, 2005.

[13] R. H. Miller \& J. H. Malinowski, Power System Operation, Tata Mc Graw Hill Professional Publishings, Flipkart.com, 3rd edition, 1994.

[14] J. Morren, S. W.H. de Haan, J.A. Ferreira, "Primary Power/Frequency Control with Wind, Turbines and Fuel Cells", Power Engineering Society General Meeting, IEEE, pp. 8, June 2006.

[15] R. Grünbaum, "Voltage and Power Quality Control in Wind Power Applications By Means of Dynamic 
Compensation", ABB Power Systems AB, AC Power Division, Vasteras, Sweden.

[16] Q. Lu, Y. Sun, S. Mei, Non Linear Control Systems and Power Systems Dynamics, Kluwer Academic Publishers, Norwell, Massachusetts, USA, 2002.

[17] M. Gopal, Control System Principles and Design, Tata Mc Graw Hill Publishing Company, New Delhi, India,2nd edition, 2005.

[18] F. L. Lewis, V. L. Syrmos, Optimal Control, Wiley Eastern Limited, Wiley.com, 2nd edition, 1995.

[19] Ibraheem, "Optimal Load Frequency Control Of An Interconnected Power System Consisting Of Reheat Thermal Plants", Dissertation Report Of Master of Science In Electrical Engineering, Aligarh Muslim University, 1987.

[20] D. E. Kirk, Optimal Control Theory, Prentice -Hall, 1st edition, 1970.

[21] L. S. Sheih, H. M, Dib, and B. C Miccinis, "Linear Quadratic Regulators with Eigen value Placemant in a Vertical Strip", IEEE Trans. On Automatic Control, Vol. 31, No. 3, pp. 241- 243, 1986

[22] Hardiyansyah, S. Furuya, and J. Irisawa, "Optimal Power System Stabilization via Output Feedback Excitation Control”, pp. 21-28, 1999.

[23] Y. C. Lee, C. J. Wu, "Damping of Power System Oscillations with Output Feedback and Strip Eigenvalue Assignment", IEEE Trans., Power Systems, Vol. 10, No. 3, pp. 1620-1626, 1995.

[24] K. Ogata, Modern Control Engineering, Pearson Education Asia, Singapore, 1st edition, 2002.
[25] T. Kailath, Linear Systems, Prentice-Hall, 1980.

[26] J. Kautsky \& N.K. Nichols, "Robust Pole Assignment in Linear State Feedback," International Journal Control, Vol. 41, pp. 1129-1155, 1985.

[27] A.J. Laub \& M. Wette, "Algorithms and Software for Pole Assignment and Observers", UCRL-15646 Rev. 1, EE Dept., Univ. of Calif., Santa Barbara, CA, Sept. 1984.

[28] B. Rabelo \& W. Hofmann, "Optimal Reactive Power Splitting with the Doubly Fed Induction Generators for Wind-Turbine", Proceedings of DEWEK, CD Wilhemshaven, Germany, October 2002.

[29] B. Rabelo, W. Hofmann, \& M. Tilscher, A. Basteck, "Voltage Regulator for Reactive Power Control on Synchronous Generators in Wind Energy Power Plants", NORPIE Trondheim, Norway, 2004

[30] F. P. De Mellow, \& C. Concordia, "Concepts of Synchronous Machine Stability as Affected by Excitation System Control", IEEE Trans. PAS, Vol. 88, pp. 316329, 1969.

[31] R. Thomas, R. Puthoff, J. Savino, \& W. Johnson, "Plans and Status of the NASA-L ewis Research Centre Wind Energy Projects", Joint IEEE/ASME Power Conf., Portland, OR, Paper no. NTIS N75 - 21795, 1975.

[32] K. R. Padiyar, Power System Dynamics, B. S. Publications, Hyderabad, India, 2nd edition, 2006.

[33] H. Hwang, L. J. Gilber, "Synchronization of Wind Turbine Generators Against an Infinite Bus under Gusting Conditions", IEEE Trans., PAS, Vol. 97, pp. 536- 544, 1978

TABLE I. OPEN LOOP

\begin{tabular}{|c|c|}
\hline POINT & $\mathbf{K}$ \\
\hline $\mathrm{P}=1.0$ & {$\left[\begin{array}{lllllllll}-0.5502 & -0.5071 & -0.0619 & 20.7782 & 0.9992 & -0.9974 & -0.0011 & 0.0000\end{array}\right.$} \\
\hline $\mathrm{P}=0.65$ & $=\left[\begin{array}{llllllll}0.1731 & -0.2482 & -0.0793 & 20.7786 & 0.9991 & -0.9937 & -0.0019 & -0.0000\end{array}\right]$ \\
\hline $\mathrm{P}=0.35$ & $=\left[\begin{array}{llllllll}0.8948 & -0.5141 & -0.0867 & 20.7796 & 0.9988 & -0.9842 & -0.0040 & -0.0001\end{array}\right]$ \\
\hline $\mathrm{P}=0.8$ & 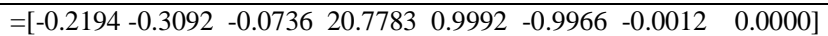 \\
\hline
\end{tabular}

TABLE II. EIG (A)

\begin{tabular}{|c|l|l|l|}
\hline \multicolumn{1}{|c|}{$\mathbf{P = 1 . 0}$} & \multicolumn{1}{|c|}{$\mathbf{P = 0 . 6 5}$} & $\mathbf{P}=\mathbf{0 . 3 5}$ & \multicolumn{1}{c|}{$\mathbf{P = 0 . 8}$} \\
\hline $1.0 \mathrm{e}+002 *$ & $1.0 \mathrm{e}+002 *$ & $1.0 \mathrm{e}+002 *$ & $1.0 \mathrm{e}+002 *$ \\
-6.5092 & -6.5093 & -6.5093 & -6.5092 \\
-0.2062 & -0.2061 & -0.2061 & -0.2061 \\
$-0.0093+0.0816 \mathrm{i}$ & $-0.0240+0.0933 \mathrm{i}$ & $-0.0321+0.0768 \mathrm{i}$ & $-0.0162+0.0886 \mathrm{i}$ \\
$-0.0093-0.0816 \mathrm{i}$ & $-0.0240-0.0933 \mathrm{i}$ & $-0.0321-0.0768 \mathrm{i}$ & $-0.0162-0.0886 \mathrm{i}$ \\
-0.0511 & $-0.0082+0.0171 \mathrm{i}$ & $0.0001+0.0394 \mathrm{i}$ & -0.0334 \\
0.0066 & $-0.0082-0.0171 \mathrm{i}$ & $0.0001-0.0394 \mathrm{i}$ & -0.0214 \\
-0.0215 & -0.0216 & -0.0216 & 0.0029 \\
-0.0111 & -0.0097 & -0.0100 & -0.0114 \\
\hline
\end{tabular}


TABLE III. Closed LoOP

\begin{tabular}{|l|ll|}
\hline $\mathrm{P}=0.8$ & $\mathrm{G}=\left[\begin{array}{ll}-0.1546 & 10.3902\end{array}\right]$ \\
\hline $\mathrm{P}=0.35$ & $\mathrm{G}=\left[\begin{array}{ll}-0.2571 & 10.3909\end{array}\right]$ \\
\hline $\mathrm{P}=0.65$ & $\mathrm{G}=\left[\begin{array}{ll}-0.1241 & 10.3904\end{array}\right]$ \\
\hline $\mathrm{P}=1.0$ & $\mathrm{G}=\left[\begin{array}{ll}-0.2536 & 10.3902\end{array}\right]$ \\
\hline
\end{tabular}

TABLE IV. EIG(A-B* $\left.\mathrm{G}^{*} \mathrm{C}\right)$

\begin{tabular}{|l|l|l|l|}
\hline $\mathbf{P = 0 . 8}$ & \multicolumn{1}{|c|}{$\mathbf{P = \mathbf { 0 . 3 5 }}$} & \multicolumn{1}{c|}{$\mathbf{P = \mathbf { 0 . 6 5 }}$} & \multicolumn{1}{c|}{$\mathbf{P = 1 . 0}$} \\
\hline $1.0 \mathrm{e}+002 *$ & & & $1.0 \mathrm{e}+002 *$ \\
$-3.2563+2.3245 \mathrm{i}$ & $1.0 \mathrm{e}+002 *$ & $1.0 \mathrm{e}+002 *$ & $-3.2563+2.3245 \mathrm{i}$ \\
$-3.2563-2.3245 \mathrm{i}$ & $-3.2563+2.3247 \mathrm{i}$ & $-3.2563+2.3245 \mathrm{i}$ & $-3.2563-2.3245 \mathrm{i}$ \\
-0.2061 & $-3.2563-2.3247 \mathrm{i}$ & $-3.2563-2.3245 \mathrm{i}$ & -0.2062 \\
$-0.0161+0.0873 \mathrm{i}$ & -0.2061 & -0.2061 & $-0.0084+0.0789 \mathrm{i}$ \\
$-0.0161-0.0873 \mathrm{i}$ & $-0.0253+0.0835 \mathrm{i}$ & $-0.0233+0.0944 \mathrm{i}$ & $-0.0084-0.0789 \mathrm{i}$ \\
-0.0291 & $-0.0253-0.0835 \mathrm{i}$ & $-0.0233-0.0944 \mathrm{i}$ & -0.0442 \\
-0.0212 & -0.0219 & -0.0219 & -0.0214 \\
-0.0100 & $-0.0100+0.0001 \mathrm{i}$ & -0.0139 & -0.0100 \\
\hline
\end{tabular}

TABLE V. POLE Placement

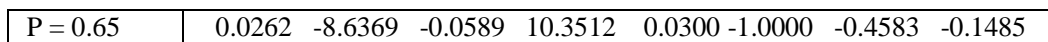

